\title{
Sodium intake in US ethnic subgroups and potential impact of a new sodium reduction technology: NHANES Dietary Modeling
}

\author{
Victor L Fulgoni III', Sanjiv Agarwal ${ }^{2}$, Lisa Spence ${ }^{3}$ and Priscilla Samuel ${ }^{3}$
}

\begin{abstract}
Background: Because excessive dietary sodium intake is a major contributor to hypertension, a reduction in dietary sodium has been recommended for the US population. Using the National Health and Nutrition Examination Survey (NHANES) 2007-2010 data, we estimated current sodium intake in US population ethnic subgroups and modeled the potential impact of a new sodium reduction technology on sodium intake.

Methods: NHANES 2007-2010 data were analyzed using The National Cancer Institute method to estimate usual intake in population subgroups. Potential impact of SODA-LO ${ }^{\otimes}$ Salt Microspheres sodium reduction technology on sodium intake was modeled using suggested sodium reductions of 20-30\% in 953 foods and assuming various market penetrations. SAS 9.2, SUDAAN 11, and NHANES survey weights were used in all calculations with assessment across age, gender and ethnic groups.
\end{abstract}

Results: Current sodium intake across all population subgroups exceeds the Dietary Guidelines 2010 recommendations and has not changed during the last decade. However, sodium intake measured as a function of food intake has decreased significantly during the last decade for all ethnicities. "Grain Products" and "Meat, Poultry, Fish, \& Mixtures" contribute about $2 / 3^{\text {rd }}$ of total sodium intake. Sodium reduction, using SODA-LO ${ }^{\otimes}$ Salt Microspheres sodium reduction technology (with 100\% market penetration) was estimated to be $185-323 \mathrm{mg} /$ day or $6.3-8.4 \%$ of intake depending upon age, gender and ethnic group.

Conclusions: Current sodium intake in US ethnic subgroups exceeds the recommendations and sodium reduction technologies could potentially help reduce dietary sodium intake among those groups.

Keywords: Sodium intake, Ethnic subgroups, Sodium reduction modeling, NHANES, Sodium reduction technology

\section{Background}

The prevalence of hypertension in America has increased over the past 20 years in men, women, Blacks, and Whites [1]. Based on 2007 to 2010 data, 33\% (about 78 million) of US adults have hypertension and African American adults have among the highest prevalence of hypertension (44\%) in the world [2]. In 2010, high blood pressure was estimated to be responsible for $\$ 156$ billion in direct and indirect health care cost [3]. Because excessive dietary sodium intake is a significant contributor to hypertension [3-9], limiting sodium intake has been recommended for the US population by US public health agencies and other

\footnotetext{
*Correspondence: agarwal47@yahoo.com

${ }^{2}$ NutriScience LLC, 901 Heatherwood Drive, East Norriton, PA, USA Full list of author information is available at the end of the article
}

expert scientific organizations, such as the American Heart Association $[5,7,10,11]$. The Dietary Guidelines for Americans 2010 [11] recommend a maximum dietary sodium intake of 2,300 $\mathrm{mg} /$ day for the general population and $1500 \mathrm{mg} /$ day for at-risk groups, including African Americans, older adults (age 51 years and above), and persons of any age with hypertension, diabetes, or chronic kidney disease (about half of the US population). The World Health Organization (WHO) [12] recommends adults consume less than 2,000 $\mathrm{mg}$ of sodium, or 5 grams of salt. Regardless of these recommendations, dietary sodium intake in the US is well above that needed for physiological function and is greater than recommended.

Sodium is primarily consumed as sodium chloride and the majority of sodium in the diet comes from sodium 
added during food processing as an ingredient for flavor, processing aid, and for food safety purposes [11,13]. Processed foods contribute more than $75 \%$ of dietary sodium intake in the US diet; about $10 \%$ of dietary sodium occurs naturally in foods and another $5-10 \%$ is discretionary salt [4].

In this study, we used the most recent (2007-2010) data from the National Health and Nutrition Examination Survey (NHANES) to estimate the current sodium intake in population subgroups and modeled the potential impact of SODA-LO ${ }^{\circ}$ Salt Microspheres sodium reduction technology on sodium intake. SODA- $\mathrm{LO}^{\circ}$ is a sodium-reduction ingredient that can reduce sodium in certain applications through its technology that turns standard salt crystals into free-flowing, hollow salt microspheres, which efficiently delivers salt taste and functionality by maximizing surface area.

\section{Methods}

\section{Study population}

NHANES, a large dietary survey of a nationally representative sample of the non-institutionalized US population, was used to assess sodium intake and its sources in the diet of ethnic subgroups in the US population [14]. The NHANES data are collected and released by the National Center for Health Statistics (NCHS) of the Center for Disease Control and Prevention (CDC), every two years. All participants or proxies provided written informed consent and the Research Ethics Review Board at the NCHS approved the survey protocol. Dietary intake data with reliable 24-hour recall dietary interviews (day one via in-person interview at the Mobile Examination Center and day two via telephone interview) using USDA's automated multiple-pass method (AMPM) were used. The data from NHANES 2007-2008 and 2009-2010 were combined for the analyses [15]. The combined sample included 3,626 Mexican American; 5,559 other Hispanic; 7,369 non-Hispanic White and 3,568 non-Hispanic Black participants ages 2 years and older. Children under age 2 years and pregnant and/or lactating females were excluded from the analyses.

\section{Estimation of sodium intake}

The USDA Nutrient Database for Standard Reference (SR) Releases 22 \& 24 were used in conjunction with the Food \& Nutrient Database for Dietary Studies (FNDDS) versions $4.1 \& 5.0$, to determine the sodium derived from foods consumed by NHANES 2007-2008 and NHANES 2009-2010 participants respectively [16-19]. Unadjusted sodium values were used in all analyses. The mean usual intakes (long-run average daily intakes) of sodium from all foods were determined using the National Cancer Institute (NCI) method [20] for a single dietary component, because sodium is consumed at some level on most days. All analyses were adjusted for the complex survey design of NHANES using the appropriate sample weight. Covariates in the usual intake models included age and gender groups, day of the week of dietary recall (weekend/weekday), and interview sequence of the dietary recall (in person versus via telephone).

\section{Estimation of food sources of sodium}

Food groups for NHANES 2007-2008 and NHANES 2009-2010 dietary intake data were defined using the USDA FNDDS 4.1 \& FNDDS 5.0 databases, respectively $[16,18]$. Data for over 7000 foods were collapsed into 9 broad categories of FNDDS food groups. Sodium consumption (mg/day) and amount of sodium as percent of total dietary intake ( $\mathrm{mg} / \mathrm{kcal}$ and $\mathrm{mg} / \mathrm{g}$ food) were computed for all FNDDS food groups.

\section{Sodium intake modeling analysis}

SODA-LO ${ }^{\oplus}$ Salt Microspheres is a sodium-reduction ingredient which can reduce sodium in certain applications through its technology that turns standard salt crystals into free-flowing, hollow salt microspheres which efficiently delivers salt taste and functionality by maximizing surface area. A $20 \%$ to $30 \%$ reduction in sodium content in 953 foods (17 foods in "Milk \& Milk Products" for 20\% reduction, 304 foods in "Meat, Poultry, Fish \& Mixtures" for 20 to $25 \%$ reduction, 20 foods in "Egg" for 25\% reduction, 30 foods in "Dry Beans, Peas, Other Legumes, Nuts \& Seeds" for 25\% reduction, 511 foods in "Grain Products" for $25 \%$ reduction, 35 foods in "Vegetable" for 20 to $30 \%$ reduction, and 36 foods in "Fats, Oils \& Salad Dressings" for $25 \%$ reduction) was modeled. Various scenarios for potential reduction in usual intake of sodium were then computed by using a $0-100 \%$ reduction factor and 10$100 \%$ market penetration. The individual reductions were computed for foods using the reduction factor and market penetration factor, and were used to model usual intake after sodium reduction.

\section{Statistical methods}

SAS 9.2 (SASs Institute, Inc.; Cary, NC) and SUDAAN 11 (Research Triangle Institute, Research Triangle Park, NC, USA,) were used for all calculations. NHANES survey weights, strata and primary sampling units were used in all calculations to adjust for oversampling of certain groups, non-response by some selected sample persons, and to adjust for the complex sample design of NHANES to ensure nationally representative results. Data are presented as means \pm standard errors $(\mathrm{SE}) . \mathrm{P}<0.01$ was considered statistically significant.

\section{Results}

Usual intakes of sodium across age, gender and ethnic groups are shown in Figure 1. Intake of sodium was 


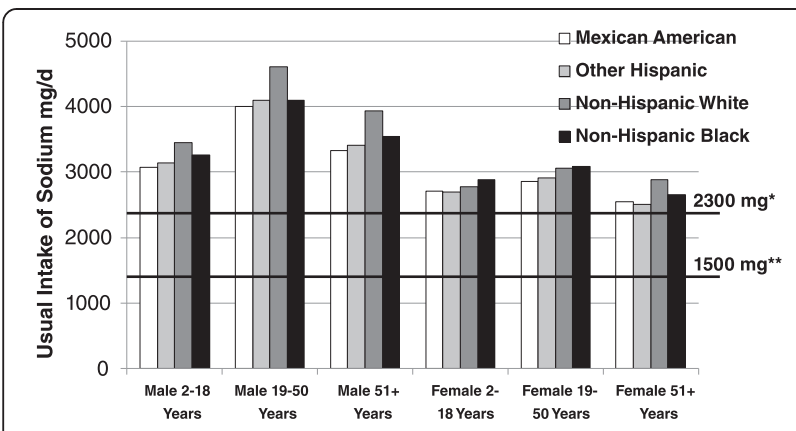

Figure 1 Usual intake of sodium by age and gender groups in population subgroups. Data from NHANES 2007-2010. Usual intakes from foods were estimated by using the National Cancer Institute method. *Dietary Guidelines for Americans 2010 recommended level for general population; **Dietary Guidelines for Americans 2010 recommended level for at risk group.

dependent on age, gender and ethnicity. The usual intake of adults (age 19-50 years) of any gender and ethnicity was higher compared to children (age 2-18 years) and older adults (age 51 years and above) of the same gender and ethnicity. The age related differences in usual intakes were much more pronounced in males than in females of any ethnicity. Males of any age and ethnic group consumed more sodium than females of the corresponding age and ethnic group. Non-Hispanic White (especially males) consumed more sodium than other ethnic groups (Figure 1). Usual intakes of all age, gender and ethnic groups were higher than $2300 \mathrm{mg} /$ day. Intakes of sodium were below $1500 \mathrm{mg} /$ day for less than $5 \%$ population of any age, gender and ethnicity (except for older adult Other Hispanic females).

Trends in sodium intake over the last 10 years (5 NHANES cycles) among adults (ages 19-50 years) and older adults (age 51 years and above) of different ethnicity are shown in Figure 2. Average sodium intake in each NHANES cycle was higher than $1500 \mathrm{mg}$ /day as well as $2300 \mathrm{mg} /$ day for all adults and older adults irrespective of gender and ethnicity. Moreover, in each NHANES cycle, male adults (ages 19-50 years) and male older adults (age 51 years and above) consistently consumed more sodium than female adults and female older adults respectively in all ethnic groups. Average intake of sodium (mg/day) during the past 5 NHANES cycles did not change significantly $(\mathrm{P}>0.01)$ for adults and older adults for any gender or ethnic group (Figure 2). Similarly, the average intake of sodium among children (ages $2-18$ years) over the past 5 NHANES cycles was always higher than $2300 \mathrm{mg} /$ day and did not change significantly $(P>0.01)$ for any gender and ethnic group (data not presented).

Sodium intake was also measured as a function of energy intake (mg/kcal) and as a function of total food intake ( $\mathrm{mg} / \mathrm{g}$ food) in addition to absolute intake ( $\mathrm{mg} /$ day) for all NHANES cycles in males and females of all ethnicities. Table 1 shows trends in sodium intake by different measures over the last 10 years (5 NHANES cycles). While there was no change in sodium intake measured as $\mathrm{mg} /$ day (absolute amount) and as $\mathrm{mg} / \mathrm{kcal}$ (function of energy intake) for male or female adults or older adults of any ethnic subgroup, sodium intake measured as a function of food intake $(\mathrm{mg} / \mathrm{g}$ food) decreased significantly $(\mathrm{P}<0.01)$ among all adult and older adult males and females of all ethnicity (except for older adult male other Hispanic). The sodium intake values in adults (age 19 years and older) of all ethnicity were $3586 \mathrm{mg}$ or $1.68 \mathrm{mg} / \mathrm{kcal}$ or $1.56 \mathrm{mg} / \mathrm{g}$ food in $2001-2002$ and $3607 \mathrm{mg}$ or $1.72 \mathrm{mg} /$ $\mathrm{kcal}$ or $1.12 \mathrm{mg} / \mathrm{g}$ food in 2009-2010.

The contribution of various food groups (FNDDS defined 9 food groups) to the sodium in the diets of US adults and older adults by population subgroups is shown in Figure 3. No major overall age, gender or ethnicity related differences were noted. "Grain Products" were the top most contributors of dietary sodium, followed by "Meat, Poultry, Fish \& Mixtures". These two food groups contributed $60-70 \%$ of total sodium intake in adults and older adults. "Milk \& Milk Products", and "Vegetables", were the next two major sodium contributors, providing more than $15 \%$ of total sodium. These four food groups ("Grain Products", "Meat, Poultry, Fish \& Mixtures", "Milk \& Milk Products", and "Vegetables") combined were responsible for more than $85 \%$ of total dietary sodium for all ethnic subgroups. The remaining five food groups ("Eggs", "Dry Beans, Peas, Other Legumes, Nuts \& Seeds", "Fruits", "Fats, Oils \& Salad Dressings", and "Sugars, Sweets \& Beverages") contributed less than $15 \%$ of the sodium in the diet (Figure 3).

Table 2 shows the maximum achievable reduction (using the maximum reduction factor and $100 \%$ market penetration) in sodium intake across all food categories to be 185-323 mg (6.3-8.4\%). A lower reduction factor and/or lower market penetration would provide lower reductions. A somewhat higher reduction is expected for non-Hispanic Whites and non-Hispanic Blacks compared to Mexican Americans and Other Hispanics (Table 2). "Grain Products" and "Meat, Poultry, Fish \& Mixtures" were the main contributors of sodium reduction, contributing to more than $80 \%$ of total sodium reduction. Sodium reduction in "Grain Products" contributed to $60-70 \%$ of total sodium reduction for Mexican Americans, other Hispanics and non-Hispanic Whites, and 50-60\% of total sodium reduction for non-Hispanic Black adults and older adults. Sodium reduction in "Meat, Poultry, Fish \& Mixtures" contributed about $16-24 \%$ of total sodium reduction for Mexican Americans, other Hispanics and non-Hispanic Whites, and about $25-30 \%$ of total sodium reduction for non-Hispanic Blacks adults and older adults (Table 3 ). 

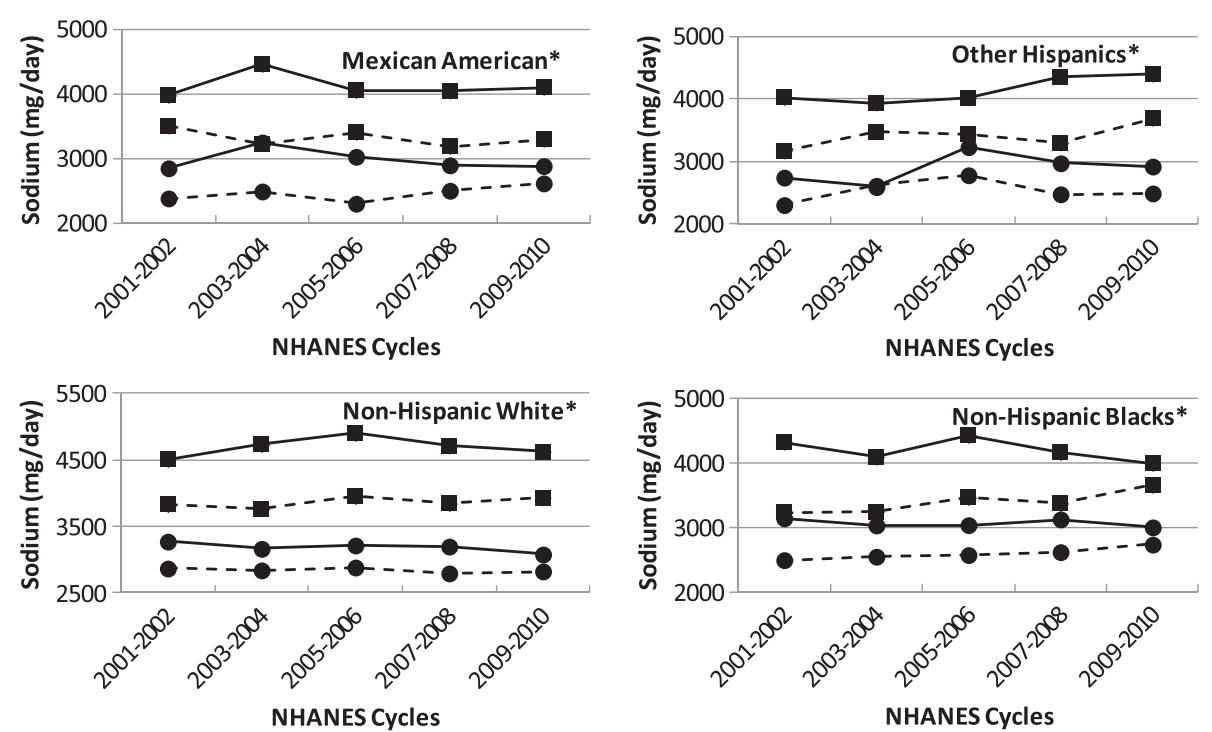

Figure 2 Sodium intake trends by age and gender groups over 5 NHANES cycles in population subgroups. Data from NHANES 2001-2010. Square: male, Circles: females, solid line: 19-50 years, dotted line: 51 + years. Usual intakes from foods were estimated by using the National Cancer Institute method. *No change over 5 NHANES cycles, $P>0.01$

\section{Discussion}

Average sodium intake across all age, gender and ethnic subgroups in 2007-2010 significantly exceeded most dietary recommendations, including those of the Dietary Guidelines for Americans 2010, American Heart Association 2010, World Health Organization 2012, Institute of
Medicine's 2005 defined Adequate Intake (AI) or Tolerable Upper Intake Level (UL) and other scientific and public health organizations $[4,11,12,21,22]$. The Dietary Guidelines for Americans 2010 recommend that at risk population groups, such as older adults (age $51+$ years) and African Americans of any age, should limit sodium

Table 1 Sodium intake trends by age and gender groups in population subgroups over 5 NHANES cycles

\begin{tabular}{|c|c|c|c|c|c|c|c|c|}
\hline \multirow[t]{3}{*}{ Ethnicity } & \multirow{3}{*}{$\begin{array}{l}\text { Age } \\
\text { (Years) }\end{array}$} & \multirow[t]{3}{*}{ Gender } & \multicolumn{6}{|c|}{ Sodium intake trend } \\
\hline & & & \multicolumn{2}{|c|}{ mg/day } & \multicolumn{2}{|c|}{$\mathrm{mg} / \mathrm{g}$ food } & \multicolumn{2}{|c|}{$\mathrm{mg} / \mathrm{kcal}$} \\
\hline & & & beta* & $\mathrm{P}^{* *}$ & beta* & $\mathrm{P} * *$ & beta* & $\mathrm{P} * *$ \\
\hline \multirow[t]{4}{*}{ Mexican American } & $19-50$ & Male & -19.33 & 0.7652 & -0.10 & $<0.0001$ & 0.03 & 0.0342 \\
\hline & & Female & -34.38 & 0.2673 & -0.14 & $<0.0001$ & 0.02 & 0.0544 \\
\hline & $51+$ & Male & -39.13 & 0.4792 & -0.09 & $<0.0001$ & -0.01 & 0.5585 \\
\hline & & Female & 53.75 & 0.1116 & -0.13 & $<0.0001$ & 0.02 & 0.1729 \\
\hline \multirow[t]{4}{*}{ Other Hispanic } & $19-50$ & Male & 110.83 & 0.0913 & -0.10 & $<0.0001$ & 0.04 & 0.0327 \\
\hline & & Female & 63.23 & 0.1697 & -0.12 & 0.0004 & 0.04 & 0.0635 \\
\hline & $51+$ & Male & 91.07 & 0.4067 & -0.11 & 0.0508 & 0.03 & 0.4286 \\
\hline & & Female & 26.09 & 0.6285 & -0.14 & $<0.0001$ & 0.03 & 0.1452 \\
\hline \multirow[t]{4}{*}{ Non-Hispanic White } & $19-50$ & Male & 23.42 & 0.5281 & -0.12 & $<0.0001$ & 0.03 & 0.0012 \\
\hline & & Female & -34.81 & 0.1798 & -0.15 & $<0.0001$ & 0.01 & 0.2341 \\
\hline & $51+$ & Male & 29.05 & 0.3438 & -0.11 & $<0.0001$ & 0.00 & 0.6550 \\
\hline & & Female & -13.25 & 0.4582 & -0.13 & $<0.0001$ & -0.01 & 0.1134 \\
\hline \multirow[t]{4}{*}{ Non-Hispanic Black } & $19-50$ & Male & -59.10 & 0.2367 & -0.14 & $<0.0001$ & 0.02 & 0.1816 \\
\hline & & Female & -18.59 & 0.6458 & -0.19 & $<0.0001$ & 0.02 & 0.0936 \\
\hline & $51+$ & Male & 100.06 & 0.0619 & -0.12 & $<0.0001$ & -0.02 & 0.3977 \\
\hline & & Female & 56.50 & 0.1167 & -0.14 & $<0.0001$ & 0.03 & 0.0242 \\
\hline
\end{tabular}

Data from NHANES 2001-2010. Sodium intake was measured as absolute intake (mg/day) as a function of energy intake (mg/kcal) and as a function of food intake $(\mathrm{mg} / \mathrm{g}$ food).

*beta - regression coefficient; ${ }^{* * P}<0.01$ significant. 

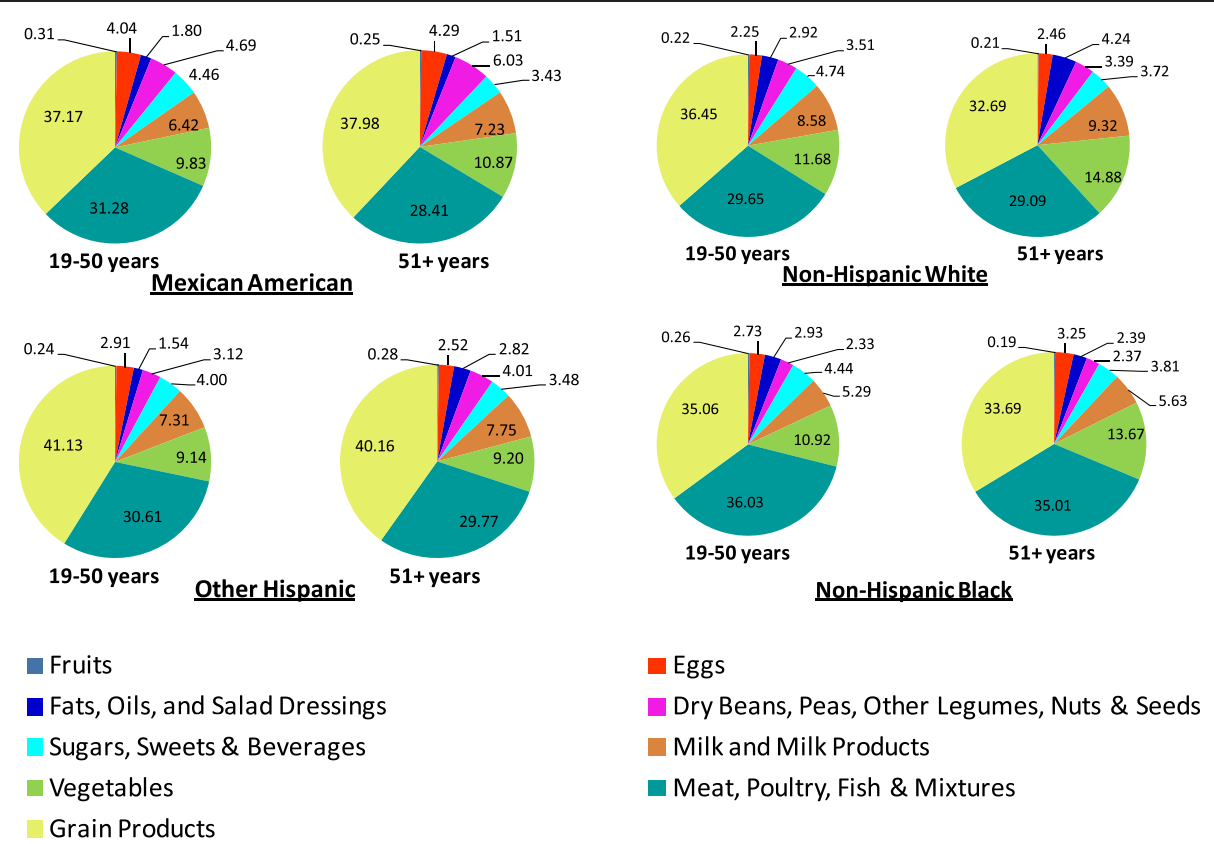

Figure 3 Dietary sodium contribution from nine FNDDS food groups by age groups in population subgroups. Data from NHANES 2007-2010. Data is presented as \% of total dietary sodium.

intake to $1500 \mathrm{mg} /$ day [11]. However, the average intake of non-Hispanic Blacks of any age/gender (except for female children and older adults) and male older adults of any ethnicity were more than twice the US Dietary Guideline recommendations and only a small proportion of the population (less than 5\%) met these recommendations. Sodium intake above recommendations is a global issue as demonstrated by high average sodium intakes in other countries [23]. Current evidence suggests that excessive sodium intake is a risk factor for hypertension and consequent health outcomes, including coronary heart disease (CHD), stroke, and mortality [5-9].

The average intake of sodium was age and gender dependent, with males consuming more sodium than females, and adults (ages 19-50 years) consuming more sodium than children (ages 2-18 years) and older adults (age 51 years and above). This observation is most likely due to higher food and caloric intake among males and adults ages $19-50$ years. In addition to age and gender dependence, the average intake of sodium was also dependent on ethnicity. The average intake of sodium was highest for Non-Hispanic Whites followed by non-Hispanic Blacks, and other Hispanics and Mexican Americans in every age and gender group (except for non-Hispanic Black female children and female adults). Earlier studies comparing ethnic subgroups also reported a higher mean intake of sodium among non-Hispanic Whites compared to nonHispanic Blacks and Mexican Americans [13,24-26]. These

Table 2 Potential sodium intake reduction with SODA-LO ${ }^{\circledR}$ Salt Microspheres (Sodium Replacement Technology) in population subgroups

\begin{tabular}{llcccc}
\hline Ethnicity & Age & Potential reduction* $\mathbf{( m g )}$ & Current intake $(\mathbf{m g})$ & Potential intake after reduction $(\mathbf{m g})$ & \% Reduction* \\
\hline Mexican American & $19-50$ years & $250 \pm 14$ & $3558 \pm 68$ & $3309 \pm 59$ & $6.8 \pm 0.3$ \\
& $51+$ years & $196 \pm 12$ & $2898 \pm 86$ & $2702 \pm 78$ & $6.8 \pm 0.4$ \\
Other Hispanic & $19-50$ years & $252 \pm 11$ & $3599 \pm 45$ & $3347 \pm 39$ & $6.9 \pm 0.3$ \\
& $51+$ years & $185 \pm 11$ & $2916 \pm 68$ & $37 \pm 63$ & $6.3 \pm 0.3$ \\
Non-Hispanic White & $19-50$ years & $323 \pm 8$ & $3903 \pm 55$ & $3581 \pm 53$ & $8.3 \pm 0.2$ \\
& $51+$ years & $242 \pm 5$ & $3320 \pm 49$ & $3078 \pm 47$ & $7.3 \pm 0.2$ \\
Non-Hispanic Black & $19-50$ years & $296 \pm 10$ & $3544 \pm 66$ & $3248 \pm 60$ & $8.4 \pm 0.2$ \\
& $51+$ years & $222 \pm 9$ & $3046 \pm 74$ & $2824 \pm 67$ & $7.2 \pm 0.2$ \\
\hline
\end{tabular}

Data from NHANES 2007-2010. Potential reduction was modeled using $20 \%$ to $30 \%$ targeted maximum reduction in sodium content in 953 foods with $100 \%$ 
Table 3 Potential sodium intake reduction with SODA-LO ${ }^{\circledR}$ salt microspheres in population subgroups by FNDDS food groups

\begin{tabular}{|c|c|c|c|c|}
\hline & \multicolumn{4}{|c|}{ Potential sodium intake reduction, $\mathrm{mg} \&(\%)$} \\
\hline & \multicolumn{4}{|c|}{ Mean \pm SE } \\
\hline & Mexican American & Other Hispanic & Non-Hispanic white & Non-Hispanic black \\
\hline \multicolumn{5}{|c|}{ All foods (953 foods; $20-30 \%$ targeted reduction in sodium content) } \\
\hline Male, $19-50$ Years & $294 \pm 20(6.9 \pm 0.4)$ & $297 \pm 15(7.0 \pm 0.3)$ & $398 \pm 13(8.7 \pm 0.2)$ & $338 \pm 13(8.3 \pm 0.3)$ \\
\hline Male, $51+$ Years & $236 \pm 19(7.3 \pm 0.5)$ & $222 \pm 18(6.7 \pm 0.5)$ & $290 \pm 7(7.4 \pm 0.2)$ & $258 \pm 14(7.2 \pm 0.2)$ \\
\hline Female, 19-50 Years & $193 \pm 10(6.7 \pm 0.3)$ & $198 \pm 9(6.8 \pm 0.3)$ & $248 \pm 7(8.0 \pm 0.2)$ & $259 \pm 14(8.4 \pm 0.3)$ \\
\hline Female $51+$ Years & $161 \pm 7(6.3 \pm 0.3)$ & $152 \pm 7(6.0 \pm 0.3)$ & $200 \pm 6(7.2 \pm 0.2)$ & $195 \pm 12(7.2 \pm 0.3)$ \\
\hline \multicolumn{5}{|c|}{ Milk \& milk products ( 17 foods; $20 \%$ targeted reduction in sodium content) } \\
\hline Male, $19-50$ Years & $2 \pm 1(0.2 \pm 0.1)$ & $2 \pm 1(0.2 \pm 0.1)$ & $4 \pm 1(0.3 \pm 0.1)$ & $0.3 \pm 0.2(0.1 \pm 0.0)$ \\
\hline Male, $51+$ Years & $0.2 \pm 0.1(0.02 \pm 0.01)$ & $0.3 \pm 0.2(0.1 \pm 0.0)$ & $5 \pm 1(0.5 \pm 0.1)$ & $1 \pm 0(0.2 \pm 0.2)$ \\
\hline Female, 19-50 Years & $2 \pm 1(0.4 \pm 0.2)$ & $2 \pm 1(0.3 \pm 0.1)$ & $5 \pm 1(0.5 \pm 0.1)$ & $2 \pm 1(0.4 \pm 0.1)$ \\
\hline Female $51+$ Years & $5 \pm 2(0.6 \pm 0.2)$ & $3 \pm 1(0.4 \pm 0.1)$ & $6 \pm 1(0.9 \pm 0.1)$ & $2 \pm 1(0.4 \pm 0.2)$ \\
\hline \multicolumn{5}{|c|}{ Meat, poultry, fish \& mixtures (304 foods; $20-25 \%$ targeted reduction in sodium content) } \\
\hline Male, 19-50 Years & $67 \pm 9(4.7 \pm 0.5)$ & $72 \pm 9(4.8 \pm 0.4)$ & $87 \pm 5(5.5 \pm 0.3)$ & $117 \pm 7(7.4 \pm 0.3)$ \\
\hline Male, 51+ Years & $44 \pm 6(4.4 \pm 0.6)$ & $39 \pm 6(3.9 \pm 0.5)$ & $59 \pm 4(4.5 \pm 0.2)$ & $79 \pm 5(5.5 \pm 0.3)$ \\
\hline Female, 19-50 Years & $44 \pm 7(5.1 \pm 0.6)$ & $43 \pm 5(4.9 \pm 0.5)$ & $53 \pm 4(5.8 \pm 0.4)$ & $92 \pm 7(8.2 \pm 0.5)$ \\
\hline Female $51+$ Years & $37 \pm 6(4.8 \pm 0.5)$ & $31 \pm 5(3.9 \pm 0.5)$ & $31 \pm 3(3.9 \pm 0.3)$ & $49 \pm 5(5.0 \pm 0.5)$ \\
\hline \multicolumn{5}{|c|}{ Eggs ( 20 foods; $25 \%$ targeted reduction in sodium content) } \\
\hline Male, 19-50 Years & $4 \pm 2(1.2 \pm 0.5)$ & $3 \pm 1(1.0 \pm 0.4)$ & $4 \pm 1(1.6 \pm 0.4)$ & $4 \pm 2(1.2 \pm 0.5)$ \\
\hline Male, $51+$ Years & $2 \pm 1(0.4 \pm 0.3)$ & $1 \pm 1(0.3 \pm 0.3)$ & $5 \pm 1(2.0 \pm 0.5)$ & $4 \pm 1(1.0 \pm 0.4)$ \\
\hline Female, $19-50$ Years & $3 \pm 1(1.3 \pm 0.5)$ & $3 \pm 1(1.3 \pm 0.4)$ & $3 \pm 1(2.1 \pm 0.7)$ & $4 \pm 2(2.0 \pm 0.7)$ \\
\hline Female $51+$ Years & $2 \pm 1(0.6 \pm 0.3)$ & $1 \pm 1(0.4 \pm 0.2)$ & $2 \pm 1(0.7 \pm 0.3)$ & $3 \pm 2(0.7 \pm 0.4)$ \\
\hline \multicolumn{5}{|c|}{ Dry beans, peas, other legumes, nuts \& seeds (30 foods; $25 \%$ targeted reduction in sodium content) } \\
\hline Male, 19-50 Years & $5 \pm 1(3.3 \pm 0.6)$ & $4 \pm 1(3.0 \pm 0.5)$ & $7 \pm 1(9.6 \pm 0.8)$ & $3 \pm 0.7(8.4 \pm 0.9)$ \\
\hline Male, $51+$ Years & $4 \pm 1(4.3 \pm 0.9)$ & $3 \pm 1(4.1 \pm 0.8)$ & $8 \pm 1(10.7 \pm 0.8)$ & $4 \pm 1(6.6 \pm 1.0)$ \\
\hline Female, $19-50$ Years & $2 \pm 1(4.0 \pm 0.7)$ & $2 \pm 0.4(4.6 \pm 0.6)$ & $5 \pm 1(8.0 \pm 0.7)$ & $2 \pm 0.5(7.4 \pm 1.3)$ \\
\hline Female $51+$ Years & $2 \pm 1(4.1 \pm 0.9)$ & $3 \pm 1(5.1 \pm 0.8)$ & $5 \pm 0.4(11.1 \pm 0.8)$ & $2 \pm 0.4(7.3 \pm 1.0)$ \\
\hline \multicolumn{5}{|c|}{ Grain products ( 511 foods; $25 \%$ targeted reduction in sodium content) } \\
\hline Male, $19-50$ Years & $195 \pm 16(13.4 \pm 0.8)$ & $195 \pm 13(12.6 \pm 0.6)$ & $253 \pm 11(15.1 \pm 0.4)$ & $179 \pm 10(13.0 \pm 0.4)$ \\
\hline Male, $51+$ Years & $166 \pm 13(14.7 \pm 0.6)$ & $158 \pm 13(13.4 \pm 0.6)$ & $176 \pm 6(14.4 \pm 0.4)$ & $145 \pm 12(13.4 \pm 0.5)$ \\
\hline Female, 19-50 Years & $125 \pm 5(11.2 \pm 0.3)$ & $132 \pm 6(11.3 \pm 0.4)$ & $156 \pm 5(14.0 \pm 0.2)$ & $126 \pm 8(11.5 \pm 0.5)$ \\
\hline Female $51+$ Years & $99 \pm 6(11.6 \pm 0.6)$ & $100 \pm 4(11.4 \pm 0.5)$ & $132 \pm 5(14.1 \pm 0.3)$ & $117 \pm 7(13.3 \pm 0.5)$ \\
\hline \multicolumn{5}{|c|}{ Vegetables ( 35 foods; $20-30 \%$ targeted reduction in sodium content) } \\
\hline Male, 19-50 Years & $18 \pm 2(5.0 \pm 0.4)$ & $17 \pm 2(5.0 \pm 0.4)$ & $37 \pm 3(7.1 \pm 0.4)$ & $29 \pm 3(8.5 \pm 0.7)$ \\
\hline Male, $51+$ Years & $15 \pm 2(4.7 \pm 0.6)$ & $14 \pm 2(4.6 \pm 0.4)$ & $25 \pm 2(4.7 \pm 0.3)$ & $18 \pm 2(4.3 \pm 0.4)$ \\
\hline Female, 19-50 Years & $15 \pm 1(4.4 \pm 0.4)$ & $14 \pm 1(5.0 \pm 0.4)$ & $20 \pm 1(5.8 \pm 0.4)$ & $28 \pm 3(7.8 \pm 0.6)$ \\
\hline Female $51+$ Years & $12 \pm 2(3.6 \pm 0.7)$ & $10 \pm 2(3.3 \pm 0.5)$ & $16 \pm 1(3.9 \pm 0.3)$ & $17 \pm 2(5.3 \pm 0.6)$ \\
\hline \multicolumn{5}{|c|}{ Fats, oils $\&$ salad dressings ( 36 foods; $25 \%$ targeted reduction in sodium content) } \\
\hline Male, $19-50$ Years & $4 \pm 1(16.1 \pm 1.3)$ & $4 \pm 0(16.4 \pm 1.0)$ & $7 \pm 1(14.4 \pm 0.9)$ & $5 \pm 1(14.4 \pm 0.9)$ \\
\hline Male, $51+$ Years & $4 \pm 1(6.0 \pm 1.6)$ & $6 \pm 1(15.8 \pm 1.3)$ & $12 \pm 1(15.5 \pm 0.6)$ & $8 \pm 1(18.6 \pm 0.9)$ \\
\hline Female, $19-50$ Years & $2 \pm 0(11.5 \pm 1.0)$ & $3 \pm 0(12.0 \pm 0.8)$ & $6 \pm 1(13.5 \pm 0.7)$ & $4 \pm 1(13.4 \pm 1.2)$ \\
\hline Female $51+$ Years & $4 \pm 1(16.1 \pm 0.8)$ & $4 \pm 1(15.6 \pm 0.8)$ & $9 \pm 1(13.6 \pm 0.6)$ & $6 \pm 1(16.4 \pm 0.8)$ \\
\hline
\end{tabular}

Data from NHANES 2007-2010. Potential reduction was modeled using 20\% to 30\% targeted maximum reduction in sodium content in 953 foods with $100 \%$ market penetration. 
observed differences between ethnic population subgroups may be related to differences in dietary patterns. While non-Hispanic Blacks consume slightly less sodium than non-Hispanic Whites, it is recommended that they limit sodium intake to $1500 \mathrm{mg} /$ day due to their likely sensitivity to sodium with a greater response to blood pressureraising effects of sodium $[27,11]$.

Our data on ethnic subgroups also showed that sodium intake has not changed in the past decade and has consistently remained higher than the Dietary Guidelines recommendations. There is very limited data available on sodium intake trends among ethnic subgroups in the US population. An analysis of 38 studies from 1957-2003 did not find any significant temporal trend in $24 \mathrm{~h}$ sodium excretion among males or females, or Blacks or Whites participants [28]. Another recent analysis of NHANES data reported a slight decline in mean sodium intake but no change in sodium density during 2003 to 2010 and suggested this to be related to declines in calorie consumption [29]. In the present study, sodium intake was also measured as a function of total food intake and total calorie intake, in addition to absolute intake. While there was no change in the absolute amount of sodium intake, we noted a significant decrease in sodium intake as a function of food intake in all ethnic subgroups over the last decade. This suggests that a reduction in the sodium content of foods occurred, but with a consequent increase in food intake during 2001-2010, potentially offsetting the decrease in sodium and resulting in no change in total sodium intake ( $\mathrm{mg} /$ day) of the population. This finding emphasizes the need for innovative food technologies to help further reduce the sodium content of foods.

Different foods contain different amounts of sodium, which is either added (for flavor, food processing, and/or food safety) or occurs naturally $[4,11,13]$. However, both sodium content of foods and the frequency of food consumption contribute to sodium intake. Often the problem of excess sodium intake is due to frequently consumed foods which might be moderate in their sodium content [4]. Studies from CDC and NCI [30,31] analyzing NHANES 2005-2006 data, reported that grain and meat products were the top contributors of sodium in the US diet. The present study, using the most recent NHANES dataset (2007-2010) for various ethnic subgroups, shows that two food groups "Grain Products" and "Meat, Poultry, Fish \& Mixtures" jointly provide 2/3 of dietary sodium, and four food groups "Grain Products", "Meat, Poultry, Fish \& Mixtures", "Milk \& Milk Products", and "Vegetables", jointly provide $4 / 5$ of the dietary sodium for all age, gender and ethnic subgroups. These data suggest that sodium reduction strategies aiming at "Grain Products" and "Meat, Poultry, Fish \& Mixtures", the two major food group sources of sodium in the diet, could have a bigger impact on dietary sodium reduction compared to other food groups.

Continued high sodium intake across the population, despite consistent recommendations to limit sodium and the accumulating evidence linking excessive sodium intake to hypertension, has led to calls for population wide interventions to reduce sodium in the US diet [13,32]. However, current sodium intake status (2007-2010 NHANES) and the sodium intake trend (2001-2010 NHANES) data presented above for population subgroups indicate that there has been no significant progress in the reduction of sodium intake. Our present dietary sodium modeling data using SODA-LO ${ }^{\circ}$ Salt Microspheres, a sodium-reduction ingredient at its potential usage level in 953 foods shows a $185-323 \mathrm{mg} /$ day reduction in sodium intake which translates to about $6.3-8.4 \%$ reduction of current sodium intake in the US population by ethnic subgroups. Utilizing this technology could add to the stepwise reduction in sodium content of foods that the food industry has been implementing.

Dietary sodium reduction is an important target for public health improvement, as reduced sodium intake has been demonstrated to reduce blood pressure and is also associated with a reduced risk of stroke and fatal coronary heart disease in adults [5-9,33,34]. Dietary sodium reduction is estimated (using statistical modeling) to be cost effective, may potentially improve overall health and provide substantial healthcare cost benefits [35-41]. Using the CHD Policy Model (a computer simulation of heart disease in US adults) to quantify the benefits of sodium reduction, Bibbins-Domingo et al. recently estimated that reducing dietary salt by $3 \mathrm{~g}$ (1200 $\mathrm{mg}$ sodium) per day would reduce CHD, stroke and myocardial infarction, prevent deaths, and save \$10-24 billion in health care costs annually [35]. Interpolation of these data [35] suggest a potential for 0.45 to $0.88 \mathrm{~mm} \mathrm{Hg}$ reduction in systolic blood pressure and $\$ 3.0$ to 5.3 billion in reductions in health care cost with a $300 \mathrm{mg} /$ day decrease in sodium intake. The present study demonstrated a possible 185$323 \mathrm{mg} /$ day reduction in current sodium intake using SODA-LO ${ }^{\circ}$, which could lead to the $300 \mathrm{mg} /$ day decrease in sodium that is attributed to blood pressure and health care cost reductions. Substantially higher potential health benefits due to sodium reduction are expected in at-risk groups, including African Americans, older adults (age 51 years and above), and persons of any age with hypertension, diabetes, or chronic kidney disease, as they may be more responsive to blood pressure-raising effects of sodium [11].

SODA-LO ${ }^{\circ}$ Salt Microspheres is a sodium-reduction ingredient that converts standard salt crystals into freeflowing, hollow salt microspheres which efficiently delivers salt taste and functionality by maximizing surface area. As with many other sodium reduction approaches, 
such a technology could modestly increase the cost of some foods, however the potential health benefits, health improvement and reduced healthcare costs from dietary sodium reduction is expected to vastly out-weigh the cost of the technology. Additionally, use of sodium reduction technologies which do not alter flavor may potentially delay the consumer's palate adaptation for less salt. However, changing consumer behavior is difficult and some attempts to lower dietary salt intake on an individual basis have largely proved to be ineffective [42]. Moreover, changing the palate may require a significant amount of time; in the interim technologies like SODA- $\mathrm{LO}^{\circ}$ Salt Microspheres can provide an immediate solution for sodium intake reduction. Further research is needed to evaluate the effects of sodium reduction in the marketplace as the sodium reduction technologies, such as SODA-LO ${ }^{\circ}$, are introduced.

A major strength of our study is the use of a large nationally representative population sample to assess the total usual intake of sodium with the NCI method. One of the limitations of our study was the cross-sectional nature of NHANES data, which prevents definitive conclusions or causality.

\section{Conclusions}

In conclusion, this study reports that current sodium intake in the US in all ethnic subgroups exceeds public health recommendations. Sodium reduction using the technology of SODA-LO ${ }^{\circ}$ Salt Microspheres could potentially reduce dietary sodium intake by $6-8 \%$ in these subgroups.

\section{Abbreviations}

Al: Adequate intake; AMPM: Automated multiple-pass method; CDC: Center for disease control and prevention; CHD: Coronary heart disease;

FNDDS: Food \& nutrient database for dietary studies; NCHS: National center for health statistics; NCl: National Cancer Institute; NHANES: National Health and Nutrition Examination Survey; SE: Standard error; SR: Standard release; UL: Tolerable upper intake level; WHO: World Health Organization.

\section{Competing interests}

VLF and SA are nutrition consultants and provide services to food industry. At the time of the research LS and PS were both full time employees of Tate \& Lyle Ingredients Americas LLC. PS has since left Tate \& Lyle. The work was funded by Tate \& Lyle Ingredients Americas LLC.

\section{Authors' contributions}

VLF - participated in the design, NHANES dietary data analysis, dietary modeling, interpretation of the data, revising the manuscript and the approval of final version; SA - participated in interpretation of the data, drafting the manuscript, revising the manuscript and the approval of final version; LS - participated in the design, NHANES dietary data analysis, dietary modeling, interpretation of the data, revising the manuscript and the approval of final version; PS - conceptualized the research, participated in the design, NHANES dietary data analysis, dietary modeling, interpretation of the data, revising the manuscript and the approval of final version.

\section{Acknowledgement}

The present study was funded by Tate \& Lyle Ingredients Americas LLC. The research and all publications arising out of or referable to it are considered proprietary data to which Tate \& Lyle Ingredients Americas LLC claims exclusive right of reference in accordance with Regulation (EC) no. 1924/ 2006 of the European Parliament and of the Council on Nutrition and Health Claims Made on Foods.

\section{Author details}

${ }^{1}$ Nutrition Impact LLC, Battle Creek, MI, USA. ${ }^{2}$ NutriScience LLC, 901 Heatherwood Drive, East Norriton, PA, USA. ${ }^{3}$ Tate \& Lyle Ingredients Americas LLC, Decatur, IL, USA.

Received: 2 October 2014 Accepted: 11 December 2014

Published: 18 December 2014

\section{References}

1. Cutler JA, Sorlie PD, Wolz M, Thom T, Fields LE, Roccella EJ: Trends in hypertension prevalence, awareness, treatment, and control rates in United States adults between 1988-1994 and 1999-2004. Hypertension 2008, 52:818-27.

2. American Heart Association: Heart Disease and Stroke Statistics-2014 Update. Circulation 2013, doi:10.1161/01.cir.0000441139.02102.80.

3. Heidenreich PA, Trogdon JG, Khavjou OA, Butler J, Dracup K, Ezekowitz MD, Finkelstein EA, Hong Y, Johnston SC, Khera A, Lloyd-Jones DM, Nelson SA, Nichol G, Orenstein D, Wilson PW, Woo YJ, American Heart Association Advocacy Coordinating Committee; Stroke Council; Council on Cardiovascular Radiology and Intervention; Council on Clinical Cardiology; Council on Epidemiology and Prevention; Council on Arteriosclerosis; Thrombosis and Vascular Biology; Council on Cardiopulmonary; Critical Care; Perioperative and Resuscitation; Council on Cardiovascular Nursing; Council on the Kidney in Cardiovascular Disease; Council on Cardiovascular Surgery and Anesthesia, and Interdisciplinary Council on Quality of Care and Outcomes Research: Forecasting the future of cardiovascular disease in the United States: a policy statement from the American Heart Association. Circulation 2011, 123:933-44.

4. US Department of Agriculture: Report of the Dietary Guidelines Advisory Committee on the Dietary Guidelines for Americans. USDAVAR, 2010.

5. Institute of Medicine: Sodium Intake in Populations: Assessment of Evidence. Washington, DC: The National Academies Press; 2013.

6. Aburto NJ, Ziolkovska A, Hooper L, Elliott P, Meerpohl JJ: Effect of lower sodium intake on health: systematic review and meta-analyses. Brit Med J 2013, 346:11326. doi:10.1136/bmj.f1326.

7. US Department of Health and Human Services, Centers for Disease Control and Prevention: Application of lower sodium intake recommendation to adults: United States, 1999-2006. MMWR Morb Mortal Wkly Rep 2009, 58:281-3.

8. Strazzullo P, D'Elia L, Kandala NB, Cappuccio FP: Salt intake, stroke, and cardiovascular disease: meta-analysis of prospective studies. Brit Med J 2009, 339:b4567.

9. Sacks FM, Svetkey LP, Vollmer WM, Appel LI, Bray GA, Harsha D, Obarzanek E, Conlin PR, Miller ER 3rd, Simons-Morton DG, Karanja N, Lin PH, DASH-Sodium Collaborative Research Group: DASH-Sodium Collaborative Research Group. Effects on blood pressure of reduced dietary sodium and the Dietary Approaches to Stop Hypertension (DASH) diet. N Engl J Med 2001, 344:3-10.

10. Appel $\amalg$, Anderson $C A$ : Compelling evidence for public health action to reduce salt intake. N Engl J Med 2010, 362:650-2.

11. US Department of Health and Human Services, US Department of Agriculture: Dietary Guidelines for Americans, 2010. 7th edition. Washington, DC: US Government Printing Office; 2010.

12. World Health Organization: Guideline: Sodium intake for adults and children. Geneva: World Health Organization (WHO); 2012.

13. Institute of Medicine: Strategies to reduce sodium intake in the United States. Washington, DC: The National Academies Press; 2010.

14. Center for Disease Control and Prevention, National Center for Health Statistics: National Health and Nutrition Examination Survey data. Hyattsville, MD: US Department of Health and Human Services, CDC; Available from: http://www.cdc.gov/nchs/nhanes/about_nhanes.htm.

15. USDA, Agricultural Research Service, Beltsville Human Nutrition Research Center, Food Surveys Research Group, U.S. Department of Health and Human Services, Centers for Disease Control and Prevention: What we eat in America, NHANES 2007-2008 and 2009-2010. Beltsville (MD): USDA ARS; Available from: http://www.ars.usda.gov/services/docs.htm?docid=13793.

16. USDA, Agricultural Research Service, Food Surveys Research Group: Food and Nutrient Database for Dietary Studies, 4.1. Beltsville, MD: 2010. 
17. U.S. Department of Agriculture, Agricultural Research Service: USDA National Nutrient Database for Standard Reference, Release 22. Nutrient Data Laboratory Home Page; 2009. http://www.ars.usda.gov/ba/bhnrc/ndl.

18. Ahuja JKA, Montville JB, Omolewa-Tomobi G, Heendeniya KY, Martin CL, Steinfeldt LC, Anand J, Adler ME, LaComb RP, Moshfegh AJ: USDA Food and Nutrient Database for Dietary Studies, 5.0. U.S. Beltsville, MD: Department of Agriculture, Agricultural Research Service, Food Surveys Research Group; 2012.

19. U.S. Department of Agriculture, Agricultural Research Service: USDA National Nutrient Database for Standard Reference, Release 24. Nutrient Data Laboratory Home; 2011. http://www.ars.usda.gov/ba/bhnrc/ndl.

20. Tooze JA, Kipnis V, Buckman DW, Carroll RJ, Freedman LS, Guenther PM, Krebs-Smith SM, Subar AF, Dodd KW: A mixed-effects model approach for estimating the distribution of usual intake of nutrients: the $\mathrm{NCl}$ method. Stat Med 2010, 29:2857-68

21. Lloyd-Jones DM, Hong Y, Labarthe D, Mozaffarian D, Appel L, Van Horn L, Greenlund K, Daniels S, Nichol G, Tomaselli GF, Arnett DK, Fonarow GC, Ho PM, Lauer MS, Masoudi FA, Robertson RM, Roger V, Schwamm LH, Sorlie P, Yancy CW, Rosamond WD, American Heart Association Strategic Planning Task Force and Statistics Committee: Defining and setting national goals for cardiovascular health promotion and disease reduction, the American Heart Association's Strategic Impact Goal through 2020 and beyond. Circulation 2010, 121:586-613.

22. Institute of Medicine: Dietary reference intakes for water, potassium, sodium, chloride, and sulfate. Washington, DC: The National Academies Press; 2005.

23. Brown IJ, Tzoulaki I, Candeias V, Elliott P: Salt intakes around the world: implications for public health. Int J Epidemiol 2009, 38:791-813.

24. U.S. Department of Agriculture, Agricultural Research S: Nutrient Intake from Food: Mean Amount Consumed per Individual, Race/Ethnicity and Age, One Day, 2005-2006. 2008. www.ars.usda.gov/ba/bhnrc/fsrg.

25. Cogswell ME, Zhang Z, Carriquiry AL, Gunn JP, Kuklina EV, Saydah SH, Yang Q, Moshfegh AJ: Sodium and potassium intakes among US adults: NHANES 2003-2008. Am J Clin Nutr 2012, 96:647-57.

26. Zhang Z, Cogswell ME, Gillespie C, Fang J, Loustalot F, Dai S, Carriquiry AL, Kuklina EV, Hong Y, Merritt R, Yang Q: Association between Usual Sodium and Potassium Intake and Blood Pressure and Hypertension among U.S. Adults: NHANES 2005-2010. PLoS One 2013, 8(10):e75289.

27. Gleiberman L: Sodium, blood pressure, and ethnicity: what have we learned? Am J Hum Biol 2009, 21:679-86.

28. Bernstein AM, Willett WC: Trends in 24-h urinary sodium excretion in the United States, 1957-2003: a systematic review. Am J Clin Nutr 2010, 92:1172-80

29. Centers for Disease Control and Prevention: Trends in the prevalence of excess dietary sodium intake - United States, 2003-2010. MMWR Morb Mortal Wkly Rep 2010, 62:1021-5.

30. Gunn JP: Sodium intake among adults - United States 2005-2006. MMWR Morb Mortal Wkly Rep 2010, 59:746-9.

31. National Cancer Institute: Sources of Sodium among the US Population, 2005-06. http://appliedresearch.cancer.gov/diet/foodsources/sodium/. Updated October 18, 2013. Accessed December 11, 2013.

32. National Salt Reduction Initiative. http://www.nyc.gov/html/doh/html/ diseases/salt.shtml.

33. He FJ, Pombo-Rodrigues S, MacGregor GAL: Salt reduction in England from 2003 to 2011: its relationship to blood pressure, stroke and ischaemic heart disease mortality. Brit Med J Open 2014, 4:e004549. doi:10.1136/bmjopen2013-004549.

34. He FJ, MacGregor GA: Effect of modest salt reduction on blood pressure: a meta-analysis of randomized trials: implications for public health. J Hum Hypertens 2002, 16:761-70.

35. Bibbins-Domingo K, Chertow GM, Coxson PG, Moran A, Lightwood JM, Pletcher MJ, Goldman L: Projected effect of dietary salt reductions on future cardiovascular disease. N Engl J Med 2010, 362:590-9.

36. Joffres MR, Campbell NR, Manns B, Tu K: Estimate of the benefits of a population-based reduction in dietary sodium additives on hypertension and its related health care costs in Canada. Can J Cardiol 2007, 23:437-43.

37. Asaria P, Chisholm D, Mathers C, Ezzati M, Beaglehole R: Chronic disease prevention: health effects and financial costs of strategies to reduce salt intake and control tobacco use. Lancet 2007, 370:2044-53.

38. Dall TM, Fulgoni VL III, Zhang Y, Reimers KJ, Packard P, Astwood JD: Predicted National Productivity Implications of Calorie and Sodium Reductions in the American Diet. Amer J Health Promotion 2009, 23:423-30.
39. Danaei G, Ding EL, Mozaffarian D, Taylor B, Rehm J, Murray CJL, Ezzati M: The preventable causes of death in the United States: Comparative risk assessment of dietary, lifestyle, and metabolic risk factors. PLoS Med 2009, 6(4):e1000058

40. Palar K, Sturm R: Potential societal savings from reduced sodium consumption in the U.S. adult population. Am J Health Promot 2009, 24:49-57.

41. Smith-Spangler CM, Juusola JL, Enns EA, Owens DK, Garber AM: Population Strategies to Decrease Sodium Intake and the Burden of Cardiovascular Disease. Ann Intern Med 2010, 152:481-7.

42. Hooper L, Bartlett C, Davey SG, Ebrahim S: Systematic review of long term effects of advice to reduce dietary salt in adults. Brit Med J 2002, 325(7365):628

doi:10.1186/1475-2891-13-120

Cite this article as: Fulgoni et al: Sodium intake in US ethnic subgroups and potential impact of a new sodium reduction technology: NHANES Dietary Modeling. Nutrition Journal 2014 13:120.

\section{Submit your next manuscript to BioMed Central and take full advantage of:}

- Convenient online submission

- Thorough peer review

- No space constraints or color figure charges

- Immediate publication on acceptance

- Inclusion in PubMed, CAS, Scopus and Google Scholar

- Research which is freely available for redistribution

Submit your manuscript at www.biomedcentral.com/submit
C) Biomed Central 